\title{
Charles Taylor: el ser humano y el bien
}

\section{Charles Taylor: the human being and good}

\author{
RUBÉN BENEDICTO RODRÍGUEZ \\ Universidad de Zaragoza
}

Recibido: 22-09-2010

Aprobado definitivamente: 17-02-2011

\begin{abstract}
RESUMEN
A partir de una lectura crítica de diversos textos fundamentales de Taylor, este artículo investiga la conexión que aparece en la obra de Charles Taylor entre el agente humano y el bien, proponiendo los rasgos de la experiencia moral que derivan de aspectos fundamentales e históricos. Se examinan algunos problemas antropológicos, éticos y políticos de las conexiones entre esta particular comprensión del ser humano y la vida buena. Asimismo, se ofrece una evaluación sobre el alcance teórico y práctico de esta propuesta señalando su posible alcance en el plano institucional.
\end{abstract}

\section{PALABRAS CLAVE \\ SER HUMANO, BIEN, AUTENTICIDAD, DIÁLOGO, RECONOCIMIENTO}

\begin{abstract}
After a critical reading of a range of Taylor's basic texts, this paper investigates the connection that appears in the work of Charles Taylor between the human agent and good, proposing traits of moral experience which derive from fundamental and historical aspects. Some anthropological, ethical and political problems which arise from the connections between this particular understanding of man and the good life are also examined. Similarly, assessment of both the theoretical and the practical scope of this proposal is given, pointing out its possible extension on an institutional level.
\end{abstract}

KEYWORDS

HUMAN BEING, GOOD, AUTHENTICITY, DIALOGUE, RECOGNITION

(C) Contrastes. Revista Internacional de Filosofía, vol. XVII (2012), pp. 47-64. ISSN: 1136-4076

Departamento de Filosofía, Universidad de Málaga, Facultad de Filosofía y Letras

Campus de Teatinos, E-29071 Málaga (España) 


\section{UNA ÉTICA SOBRE EL SER HUMANO Y SUS METAS}

EL PRESENTE ESTUDIO SE ENMARCA en una reflexión sobre la relación que se establece entre el ser humano y el bien, ofreciendo un ideal de vida buena que sirva para perfilar la disposición normativa de la ética. La ética tradicional situaba a la persona en el centro de su atención ocupándose de forjar un carácter (êthos) dirigido a la consecución de la vida buena (cf. Aranguren 1994, pp. 174-180). La construcción de un buen carácter individual y comunitario se consideraba una tarea práctica a la que debían entregarse las organizaciones y las instituciones. En este tipo de éticas la justicia se asumía que la reflexión sobre la justicia no podía separarse de la indagación sobre la naturaleza de la vida buena y la consideración de los fines humanos más elevados. ${ }^{1}$

Si se acepta este planteamiento, la ética deberá atender a las capacidades constitutivas de la identidad moral de las personas, investigando aquellos aspectos de lo humano que sirvan de guía para llevar a cabo una vida buena. Desde este prisma, se propondrá a continuación una indagación sobre algunos de los textos fundamentales en la obra del filósofo canadiense, Charles Taylor, con el fin de señalar los elementos constitutivos más relevantes de la condición ética humana. Dicha investigación revelará un conjunto de capacidades que alumbrará sobre los derechos y deberes, buscando un equilibrio entre la autonomía individual y el orden comunitario que reconozca el papel que juegan los valores y la esfera de los sentimientos en la inspiración de las normas reguladoras de la acción.

Esta interpretación de la obra de Taylor articulará un discurso antropológico que, aun reconociendo el carácter abierto de la vida humana en cuanto ésta puede adoptar diferentes configuraciones culturales, describirá una ontología de lo humano moral a la que se le atribuye especial relevancia para encarar las cuestiones relativas a la organización de la vida, tanto a nivel individual como comunitario. Finalmente, se ofrecerá un examen crítico de las principales tesis desplegadas a lo largo de esta exposición y una evaluación sobre las posibilidades prácticas que emergen de este planteamiento.

\section{Charles TAYlor: UNA ÉTICA DEL BIEN}

Uno de los aspectos más relevantes del trabajo de Taylor es su pretensión de efectuar una investigación evaluadora sobre la autointerpretación que el ser humano hace de sí mismo. Con este propósito, su obra muestra un catálogo de facetas que explicitan lo que significa ser un agente humano, una persona o

1 Este enfoque se halla, por ejemplo, en Aristóteles, para quien la determinación del modo de vida más deseable resulta previa a la definición sobre la naturaleza de la constitución ideal. (Aristóteles, Política, 1288 b 5). 
un yo. Este conjunto de rasgos se refieren a los elementos fundamentales de la experiencia moral, aunque éstos se vean influidos por ciertos condicionantes históricos que operan en la constitución de la identidad, formando entre ambos un «inevitable marco de referencia» (Taylor 1989, pp. 3-24). En consecuencia, la exploración de Taylor combina el análisis fenomenológico con el estudio hermenéutico porque, a su juicio, la pregunta por la identidad humana no puede ser contestada sin atender a los elementos históricos de autocomprensión. De hecho, la mera pregunta por la identidad requiere ya de un cierto desarrollo en la comprensión que tenemos de nosotros mismos y que se efectúa sólo a partir de un determinado momento de la historia.

En síntesis, la actual investigación muestra un intento por enunciar los rasgos definitorios de la vida del agente humano, hallados en la obra de Taylor, que pueden concebirse como capacidades que abren el yo al espacio moral. Este conjunto de rasgos no aparece sistematizado en ninguno de los trabajos del canadiense y, por lo tanto, supone una selección e interpretación que podría ser completada, modificada o cuestionada. A pesar de las posibles objeciones a esta selección, la importancia y reiteración que el trabajo de Taylor manifiesta sobre determinados aspectos de la experiencia moral permiten ofrecer un bosquejo de sus caracteres básicos. Respondiendo a este objetivo, se concederá especial relevancia a los siguientes caracteres del agente humano: la orientación al bien, la libertad situada, la autenticidad, el diálogo y la lucha por el reconocimiento.

\section{II.1. LA ORIENTACIÓN AL BIEN}

Una de las ideas centrales en el pensamiento de Taylor es que la identidad del agente se define por su orientación moral. En su obra magna, Sources of the Self, el filósofo canadiense despliega la tesis que afirma la conexión entre la identidad del sujeto y el bien (cf. Taylor 1989, pp. 25-52). ${ }^{2}$ El yo no consiste solamente en dirigir la acción estratégicamente a la luz de ciertos deseos o capacidades: ser un agente humano implica tomar posición respecto al bien porque «la individualidad y la moral, son temas que van inextricablemente entretejidos» (Taylor 1989, p. 3).El sujeto que Taylor describe consiste, sobre todo, en ser situación, en ser una posición que viene definida por el tipo de respuestas que se ofrecen a las cuestiones de valor que se le plantean. De manera que una de las características fundamentales del ser persona «es existir en un espacio definido por distinciones de valor» (Taylor 1985b, p. 3).

Tales cuestiones morales o espirituales encuentran su lugar siempre en un marco de referencia que ayuda a los sujetos a dar sentido a sus vidas y a

2 Para un análisis crítico detallado de esta cuestión pueden consultarse Smith (2002) y Kerr (2004). 
desplegar su identidad. El agente humano se halla abierto a ese marco referencial en el que ejerce distinciones de valor, «discriminaciones cualitativas» (Taylor 1989, p. 19), entre lo que considera superior o inferior, mejor o peor, y esas discriminaciones de tipo cualitativo dan lugar a «valoraciones fuertes» (Taylor 1989, p. 20). En efecto, el marco referencial constituye un horizonte de opciones morales con sentido dentro del cual el agente humano toma posición, se orienta y actúa. Dentro de ese marco referencial, el sujeto selecciona objetos de «fuerte valoración» efectuando una discriminación en la que jerarquiza los bienes detectados que repercutirán en las exigencias de la justicia. De esta manera es como, por ejemplo, el deseo de vivir bien pasa a formar parte de la esfera de la obligación moral.

Puede observarse que la «evaluación fuerte» desempeña un papel central en el razonamiento moral ordinario de la persona posibilitando «las discriminaciones de bien y mal, noble y bajo, virtuoso y vicioso, y similares, por las que distinguimos entre estos términos y por lo que alguno de ellos es incomparablemente superior» (Taylor 2007, p. 544). ${ }^{3}$ La comparación es un elemento central, pero lo relevante de la «evaluación fuerte» es que la convalidación de lo que consideramos incomparablemente valioso no depende de nuestros propios deseos, inclinaciones o elecciones, sino que es independiente de ellos. Más bien, las «evaluaciones fuertes» son portadoras de los criterios por los que ejercemos tales discriminaciones. Cuando valoramos algo de manera «fuerte» apreciamos una disposición hacia aquello que consideramos mejor o superior, dotando a nuestra apreciación de un carácter más duradero que los simples deseos, emociones o reacciones. Esta «fuerza» emerge porque nos referimos a un poder motivador que se erige por encima de aquellos deseos que no implican ningún compromiso personal. Además, la «valoración fuerte» remite a una pretensión de ser compartida, a una comunicabilidad de principio, desde el momento en que, al mantener una convicción y expresarla a través de la palabra o la acción, estamos sometiendo dicha valoración a la aprobación de los otros, de manera directa o indirecta. Por lo tanto, efectuar «valoraciones fuertes» implica desplegar la capacidad de reflexión para expresar, en un lenguaje articulado, lo que hace más valiosas nuestras preferencias respecto a otras. En esta reflexión que implica la propia valoración, la articulación consiste en efectuar un contraste dentro de un campo de descripciones de valor dadas, en relación con el tipo de vida al que se aspira y al que se le atribuye un elevado estatus de valor. De este

3 Este concepto que Taylor utiliza para acometer contra la influencia del «naturalismo» en el plano de las teorías morales ha sido objeto de análisis y discusión en diversas obras suyas: Taylor (1989, pp. 332-337), (1985a, pp. 15-44), (1985b, pp. 211-229); y también en trabajos ajenos: Laitinen (2008), Abbey (2004), Flanagan (1996, pp. 142-170), Weinstock (1994, pp. 171-193). 
modo, la identidad se constituye a través de «valoraciones fuertes» que sirven para orientarnos en el espacio moral dirigiéndonos hacia bienes que apreciamos en función de cómo deseamos vivir. Y en tanto nos preguntamos cómo queremos vivir, sometemos a examen crítico nuestras valoraciones. Por eso se dice que una «valoración fuerte» entraña los criterios por los que juzgamos nuestros deseos. En definitiva, la justificación forma parte de la fuerza de una valoración porque obliga a plantearse las razones que motivan las preferencias que adoptamos. De ahí que en su remisión a razones sean objeto de «fuerte valoración» aquellos bienes que se perciben como un compromiso que reclama nuestra adhesión particular y concebimos como objeto de potencial validez general o, al menos, de reconocimiento.

Con este conjunto de nociones, Taylor se refiere a lo que en el fondo de la experiencia de todo sujeto aparece y remite a un trasfondo de cuestiones que «atañen a lo que hace que valga la pena vivir» (Taylor 1989, p. 4). Este trasfondo queda constituido por la propia concepción de lo que se considera una vida buena, significativa, plena o floreciente, y traza el horizonte «que utilizamos para sentar las bases de las obligaciones morales que reconocemos» (Taylor 1989, p. 3). El resultado es que podemos interpretar que los deberes derivados de las exigencias de justicia se conectan con nuestra concepción de lo que es una vida mejor. Expliquemos con mayor atención el tipo de relación que se establece entre una y otra dimensión de la ética, según se deriva de la teoría tayloriana.

La orientación al bien se convierte en un existencial de la vida moral, ya que nuestra capacidad para valorar en sentido «fuerte» constituye un rasgo universal de nuestro estar en el mundo que va más allá de la mera proyección de nuestros deseos y nos insta a comprometernos con ciertas cosas que apreciamos del mundo. Esa orientación hacia el bien, cuya dirección fundamental asumimos a través de «discriminaciones cualitativas» que conducen a «valoraciones fuertes», implica una jerarquización de los bienes que sirve para definir nuestras prioridades. Así sucede que toda vida moral se encuentra obligada a efectuar una estructuración jerárquica de los bienes que suscribe, hasta alcanzar los «hiperbienes» (Taylor 1989, pp. 63-73) que constituyen el objeto de las valoraciones cualitativas de rango superior. Y una vez definidos, a través de una articulación, los bienes que forman los ideales superiores hacia los que orientar la vida moral, se supeditarán a ellos los bienes juzgados inferiores; de forma que este reconocimiento se hace condición de la adhesión e implicación del agente humano. De esta manera es como nuestro mapa moral queda delimitado por el tipo de vida buena que queremos llevar a cabo.

Sin embargo, debe considerarse que estos «hiperbienes», que trazan el mapa de referencias últimas que utilizamos para efectuar nuestras «valoraciones», son variables en la cultura y adoptan diversos contenidos, por lo que organizan un horizonte conflictivo en el que se mueve toda vida moral. Esta condición de 
pugna entre bienes tendrá consecuencias a la hora de confeccionar una ética normativa, como veremos más adelante. De momento, señalemos que Taylor reconoce la existencia de diversos tipos de bienes que corresponden a distintas concepciones de ser humano y orientan de modos diferentes la acción, y que, de hecho, recoge algunos de los diversos tipos centrales de aspiraciones humanas presentes en el contexto occidental (cf. Taylor 1985b, pp. 230-242).

Profundizando en las cuestiones relativas a la fenomenología de la experiencia ética, el canadiense se pregunta qué es lo que faculta a los seres humanos para obrar bien, y resuelve que existen unas realidades constitutivas cuya contemplación provoca un sentido de admiración y reverencia que capacita para vivir en conformidad con ellas. Dichas realidades constitutivas operan a modo de «fuentes morales» (cf. Taylor 2007, pp. 245-259, Taylor 1989, pp. 94-96) cuyo poder motivador concede al agente humano la fuerza para orientarse hacia el bien y comportarse de acuerdo a él. Por consiguiente, la idea de motivación última también forma parte integrante del «inevitable marco de referencia» de la vida moral; aunque, de nuevo, este nivel muestre un carácter fundante conflictivo al presentar ante el sujeto diversas opciones.

En definitiva, este análisis de la experiencia moral subraya la capacidad de realizar «valoraciones fuertes» como una característica propia de la definición del sujeto humano. La «valoración fuerte» señala una correlación entre la identidad humana y el bien, estableciendo una vinculación entre el examen de la propia identidad y la acción ética, donde los bienes se convierten en «bienes constitutivos» porque forman parte fundamental de la identidad del sujeto (Taylor 1989, pp. 91-107). Los bienes que reconocemos nos «constituyen» porque nos ordenan y nos indican ciertos deberes. Esta explicación pone de manifiesto la relación existente entre cómo nos concebimos a nosotros mismos y cómo concebimos el bien; porque la respuesta a la pregunta por la identidad humana se conecta -como sugiere la penetrante lectura de Sources of the Self por parte de Ricoeur- con la respuesta que ofrecemos a la pregunta: «¿Cómo debería yo vivir?», considerada una cuestión más fundamental que aquella otra: «¿Qué debo hacer?» (Ricoeur 2008, p. 159).

\section{II.2. LA LIBERTAD SITUADA}

Las nociones de «valoración fuerte» $\mathrm{y}$ «bien constitutivo» nos trasladan a un universo en el que algunas cosas nos reclaman, nos ligan y nos obligan a tomar interés en ellas. Aquellas cosas que poseen un valor incondicionado, no instrumental y, por lo tanto, cuyo valor no depende de los beneficios que reportan al individuo, nos abren a una dimensión más completa de la moralidad y, en consecuencia, del ser persona. Si esta argumentación es correcta, se infiere que la libertad se mueve entre bienes cuyo valor no depende tanto 
de las preferencias de facto del sujeto, de sus gustos o inclinaciones, como de su potencial para hacerle vivir una vida plena. Sin embargo estas ataduras no supondrán una restricción a la libertad humana, sino la posibilidad de llenar la libertad de contenido moral escapando al cálculo de intereses y permitiendo la realización personal.

Las personas se definen por la aspiración a ciertos bienes que constituyen metas hacia las que dirigirse. Pero la elección de los fines, cuando se trata de orientar una vida, no se efectúa desde el vacío, ni se limita a ser la expresión de deseos brutos, sino que depende de aquellos bienes que al sujeto se le presentan como significativos con tal grado de intensidad que los asume como propios (cf. Taylor 1997, 285-306). Aquí juega un papel crucial el hecho de que las cosas adquieran importancia sobre un «fondo de inteligibilidad»-al que Taylor denomina «horizonte» (Taylor 1989, pp. 16-17)- que permite la expresión culturalmente definida de los significados, dotando de sentido a las elecciones del agente humano. De modo que el sujeto que emerge de esta visión es un «yo situado» en el que el contexto es ineludible: donde si la elección ha de ser un ejercicio efectivo de libertad, tendrá que suponer la capacidad para hacer «discriminaciones» sobre ese trasfondo de sentido configurado por el «horizonte» (cf. Taylor 1989, pp. 29 y ss).

La acción libre consistirá en orientar la conducta hacia metas motivadoras que sean percibidas por el sujeto como significativas y, en consecuencia, deseables, fundando la libertad en la capacidad del sujeto para reflexionar sobre sus propios deseos y, posteriormente, orientar su vida hacia los fines que se propone. Pero si la elección requiere de una distinción sobre los deseos, el agente debe reconocer adecuadamente lo que es de vital importancia para él y ser capaz de superar o neutralizar aquellos obstáculos que pervierten su verdadera motivación, lo cual requiere «haber alcanzado cierto grado de claridad y de comprensión sobre sí mismo.» (Taylor 1985b, p. 229). ${ }^{4}$

Atendiendo a la cuestión de la motivación hacia el bien, según se expone en Sources of the Self (1989, pp. 314-320) y en la más reciente A Secular Age (2007, pp. 134-136 y 473-495), el proceso de secularización, que toma impulso definitivo en el siglo XVIII, supone el nacimiento de nuevas alternativas en el plano de las «fuentes morales», abriendo dos perspectivas distintas de exploración moral entre las que se debate la identidad del sujeto moderno: la primera, se asocia a un agente desvinculado que pretende conseguir, a través de la desvinculación, un cierto orden y autocontrol; un sujeto que encuentra en una interioridad autogenerada sus propias fuentes; y la segunda, reside en las honduras de la naturaleza, tal y como se reflejan en el interior del sujeto, en

4 La máxima socrática «conócete a ti mismo» con su llamada a una «vida examinada» late, pues, en el fondo de toda vida moral. 
su propia naturaleza, en sus deseos o sentimientos más verdaderos. Según esta última perspectiva, el sujeto tiene acceso a su propia significación a partir de la exploración vinculada sobre su naturaleza interior, resultando que la meta de la autoexploración no será el control desvinculado, sino la vinculación, la adaptación a la verdadera naturaleza del agente humano.

Estas dos «fuentes morales» suponen dos modelos de modernidad que componen un «horizonte fracturado» (cf. Taylor 1989, 305-320) en el que la conflictividad forma parte insoslayable de la constitución del sujeto moral. Sobre estas dos vías de acceso a la interioridad que son, a la vez, dos diferentes instancias movilizadoras de las energías morales, cabe señalar que el canadiense percibe como declive el hecho de que la razón desvinculada autoproductora de sentido haya desplazado la vía expresivista de acceso a una naturaleza que nos contiene y nos supera. Sin embargo, se insiste en que esta otra línea de exploración del bien no ha sido rebasada completamente. En efecto, Taylor plantea una recuperación que, apoyándose en la tradición romántica, recobre el significado a través de la reflexividad humana. En esta concepción se supone que, sirviéndonos del concurso simultáneo de nuestra razón y nuestro sentimiento, tendremos acceso a una interioridad que refleja un cierto orden externo a nosotros mismos (cf. Taylor 1989, pp. 363-388). En resumen, puede decirse que Taylor se propone complementar la influencia del racionalismo de la Ilustración, que pretende alcanzar el bienestar y la emancipación a través del control y la manipulación de cuanto nos rodea, con un expresivismo que defiende la elaboración de significados a través de la interpretación.

Por supuesto, se asume que la autonomía ocupa un lugar central en las demandas de la civilización occidental moderna, pero se avisa que una comprensión de la autonomía que suponga una libertad radical y desvincule al sujeto de la naturaleza exterior e interior, privará de sentido a la elección y levantará barreras entre los propios seres humanos. Si la autonomía pretende ser un valor universalizable, entonces debe enmarcarse en un contexto que reconozca la importancia de aquellos objetos de valoración que tienen importancia con independencia del propio individuo. Puede parecer una paradoja, pero la defensa de la autonomía individual se resquebraja si no se atiende a nuestra responsabilidad con el mantenimiento y la mejora de aquellos bienes que nos reclaman y que, de algún modo, nos superan. Aquí es donde aparece la particular comprensión que Taylor ofrece de la «autenticidad».

\section{II.3. LA AUTENTICIDAD}

En la constitución de un agente moral moderno y pleno, Taylor destaca el papel desempeñado por la noción de «autenticidad», defendiendo una ética en la que el individuo sea fiel a sí mismo y escoja su propio modo de vida (cf. Ta- 
ylor 1991). En este sentido, señala que la «autenticidad» se ha convertido, como resultado de nuestra propia historia cultural, en una capacidad esencial de las personas, dejando claro que nadie puede ni debe decidir por ellas. La importancia adquirida por este ideal señala un compromiso con la modernidad del sujeto reflexivo y con una definición de la persona caracterizada por la facultad de la autonomía, la creación y la originalidad.

Cuando se explora la noción de «autenticidad» como ideal moral, el método vuelve a ser, como otras veces, una combinación de hermenéutica que investiga la genealogía de esta noción en los textos fundamentales del pensamiento occidental y de fenomenología que explora la condición humana. Atendiendo a la primera de las estrategias metodológicas, se muestra que la autenticidad se erige en ideal moral de manera asociada al giro subjetivo de la cultura moderna, «cuando estar en contacto con nuestros sentimientos toma una significación moral decisiva y se convierte en algo que tenemos que alcanzar si queremos ser fiel y plenamente seres humanos» (Taylor 1994, p. 28). Su punto de partida remite a una noción según la cual los seres humanos deben escuchar la voz moral que se halla en su interior y atender a su sentimiento intuitivo de lo que está bien o mal. A juicio de Taylor, sería Rousseau el precedente romántico que provee al sujeto moderno de la necesidad de buscarse en el interior para encontrar su verdadero yo. De Rousseau se hereda la importancia que poseen la autoexpresión, la originalidad y la imaginación como facultades que el sujeto debe desarrollar para ser «auténtico» (cf. Taylor 1994, p. 29).

A delimitar esta noción contribuye Herder, quien aportará que cada persona tiene su forma original de ser humana y debe vivir su vida de acuerdo a su propio modo de ser. Herder expresa la obligación de vivir de acuerdo a la propia originalidad e implica que cada individuo tiene un camino original que debe transitar (cf. Taylor 1991, pp. 28-29). También Wilhelm von Humboldt favorecerá el impulso de este ideal moral a través de su defensa del poder de la individualidad y de la originalidad. Así, hasta definir la noción de autenticidad que llegamos a conocer en nuestros días y que hace referencia a ser fiel a uno mismo y al particular modo de ser de cada uno (cf. Taylor 1994, p. 28).

Sin embargo, el ideal de autenticidad cobija en su seno formas de autorrealización erróneas que deben ser corregidas para recuperar su fuerza moral. La tesis según la cual la identidad individual se origina a partir de la propia interioridad de cada persona, degenera cuando se confunde con crear la propia identidad aisladamente, o con buscar la autorrealización sin considerar las exigencias que superan al propio individuo y sin tener en cuenta a los demás. La capacidad autolegisladora del sujeto moral no debe ceñirse exclusivamente a su capacidad de autodeterminarción; la autonomía debe complementarse con el reconocimiento de las estructuras intersubjetivas de significación. Así, la vida moral «auténtica» se desarrolla teniendo en cuenta en igual medida dos polos 
de identificación: por un lado, «(I) creación y construcción así como descubrimiento, (II) originalidad, y con frecuencia (III) oposición a las reglas de la sociedad e incluso, en potencia, a aquello que reconocemos como moralidad», pero, también, por otro lado, «(I) apertura a horizontes de significado (pues de otro modo la creación pierde el trasfondo que puede salvarla de la insignificancia) y (II) una autodefinición en el diálogo» (Taylor 1991, p. 67).

El problema que Taylor detecta reside en que la progresiva infiltración de cierto expresivismo simplificado manifiesta una perspectiva individualista que defiende solamente la parte autocreadora y original del ideal de autenticidad, dejando de lado aquellos componentes también constitutivos de esta noción que valoran la definición dialógica del sujeto y los horizontes de significación. Y hay que tener cuidado, porque si se omiten los horizontes de significado, entonces cualquier opción es plausible, ya que el sujeto no encontrará el sentido en ninguna de ellas. Esto sucede, por ejemplo, cuando la «cultura del narcisismo» (cf. Taylor 1991, p. 55) convierte a la propia elección en un valor. La libertad de elección, sobre asuntos importantes relacionados con nuestra orientación en la vida, sirve al ideal de «autenticidad» en tanto considera que uno es fiel a sí mismo al escoger por sí solo el modo de vida que desea realizar, pero deviene banal cuando la única razón aducida a favor de la propia elección es la elección misma. La persona no es simplemente un sujeto independiente y neutro que elige su modo de vivir en función de preferencias arbitrarias o puntuales: adoptar este enfoque significa abrir las puertas al vaciado moral y político de la vida individual y comunitaria.

Sin embargo, esta crítica no implica la renuncia al ideal que la «autenticidad» representa; al contrario, Taylor muestra que dentro de nuestra tradición -en concreto, en el movimiento romántico- se encuentra una filosofía que pretende enmarcar al sujeto en un contexto más amplio que el de la pura individualidad autoelectora de fines egocéntricos y narcisistas. Y para fundamentar su propuesta, extrae las consecuencias que se derivan de la concepción dialógica del agente humano y de su racionalidad.

\section{II.4. LA DEFINICIÓN EN EL DIÁLOGO}

Nuestro filósofo asegura que somos seres dialógicos porque nos convertimos en seres humanos plenos por medio de la adquisición de ricos lenguajes de expresión humana (cf. Taylor 1991, pp. 33-35). Esos lenguajes nos ayudan a definirnos a nosotros mismos contra un trasfondo de lo que tiene importancia, aprendiendo a orientarnos en el espacio moral a través de «redes de interlocución» (cf. Taylor, 1989, p. 36) que nos sirven para reflexionar sobre los bienes que se nos presentan y efectuar una articulación jerárquica de los mismos. 
Sin embargo, esas formas de comunicación no son autogeneradas, sino co-generadas entre todos. Por lo tanto, si la mente humana es dialógica y la identidad se desarrolla en un marco comunitario, aunque la autenticidad entrañe originalidad, esa originalidad debe darse desde la comprensión de lo común, situándose en relación con un lenguaje compartido. Desde esta perspectiva, las formas de autorrealización que desechen estos condicionantes compartidos expresarán un desajustado individualismo egocéntrico. Por el contrario, la apelación al verdadero ideal de autenticidad revelará que el sujeto debe encontrar la definición de sí mismo, su propia realización, en causas que resulten importantes vistas contra un fondo de inteligibilidad. En efecto, si la elección, sobre cuestiones que no sean triviales, tiene algún valor es porque se considera que «ciertas cuestiones son más significativas que otras», y ello implica que independientemente de la propia voluntad o de lo que yo determine, existe algo que posee valor o nobleza y, por esta razón, es «significativo en la configuración de mi propia vida» (Taylor 1991, p. 39).

Vemos que las personas sólo pueden hallar una identidad «auténtica» en metas que reflejen algún bien, y esos bienes no pueden depender exclusivamente de la propia elección. Una autorrealización «auténtica» debe atender a aquellas exigencias que emanan de nuestros relación dialógica con los demás. De manera que las formas de autorrealización que desoyen los reclamos de la sociedad o de la naturaleza, que niegan el valor que reside en la historia común, en las responsabilidades solidarias o en cosas de este tenor, destruyen las condiciones de significación, y, en ese caso, abandonan las estipulaciones que reclama la «autenticidad».

Por otro lado, el factor creativo de la «autenticidad» requiere la posibilidad de elegir entre fines y cursos de acción distintos que manifiesten la originalidad del sujeto en la expresión de su ser auténtico. La idea es que yo me proveo de autenticidad moral cuando encuentro «lo que resulta significativo en mi diferencia con respecto a los demás» (Taylor 1991, pp. 35-36). Aunque si, por ejemplo, un individuo se define a sí mismo por su estatura o por el color de su pelo, no puede pretender hallar reconocimiento en esa expresión de su autenticidad, porque no está manifestando una autodefinición de sí mismo que sea reconocible. Las personas sólo pueden encontrar su propia identidad y ser fieles a sí mismas si, por un lado, persiguen una meta que hayan elegido autónomamente y, por otro lado, dicha meta contiene un significado reconocible. El problema reside en que, en ocasiones, la significación sólo tendrá un alcance personal, o sólo será percibida por un reducido grupo de personas. Por este motivo, cuando la identidad reclama la adhesión a significados que necesitan del reconocimiento del resto de la sociedad, el diálogo será la única estrategia para efectuar un establecimiento conjunto de los significados reconocibles. Por consiguiente, cuando se trata de hallar un reflejo institucional a las demandas de una identidad 
«auténtica» construida en torno a significados particulares, el reconocimiento se convierte en un requisito indispensable.

\section{II.5. LA NECESIDAD DE RECONOCIMIENTO}

Uno de los rasgos integrantes del ideal de «autenticidad» requiere la afirmación de las particularidades y de las diferencias, lo que justifica que las instituciones públicas respondan a las exigencias de reconocimiento de los ciudadanos, en lugar de practicar una política de la homogeneización cultural y la asimilación. Esta posición, en la práctica, conduce a adoptar una fórmula de convivencia que vaya más allá de la tolerancia, organizando institucionalmente en un marco pluralista la diversidad de intereses e identificaciones emanadas de la heterogeneidad cultural a la que parecen abocadas las sociedades modernas.

El modo en que se justifica la atención de las instituciones públicas hacia las diferencias alude a una interpretación fenomenológica del ser humano que descubre la genealogía social de la identidad: dado que la identidad depende de la interpretación que una persona hace de sí misma y de sus características definitorias fundamentales como ser humano, en virtud de la naturaleza dialógica a través de la cual se moldea la identidad, es importante que los demás nos reconozcan, por un lado, como personas iguales a ellas, pero, por otro lado, como personas con peculiaridades. Nuestra fragilidad moral se descubre en el hecho de que construimos nuestras opiniones sobre nosotros mismos con la ayuda de los juicios aprobatorios y reprobatorios de nuestros semejantes; de manera que existe una relación genética entre reconocimiento e identidad, o más específicamente, entre el reconocimiento recíproco generado a través de la interacción social y el desarrollo moral de la autoconciencia. Si tanto el reconocimiento como la formación de la identidad dependen de un modo crucial de la relación dialógica con los otros, y asumimos que el reconocimiento puede fracasar, entonces resultará que el reconocimiento «no es sólo una cortesía que debemos a los demás, sino una necesidad humana vital» (Taylor 1994, p. 26).

Ahora bien, es evidente que no todas las demandas identitarias que solicitan reconocimiento deben ser satisfechas por las instituciones jurídicas y políticas. La igualdad de valor de los diferentes modos de vida, en lo que atañe a sus aspectos fundamentales, no es algo que se conceda a priori, porque su valor no puede estar basado en su mera diferencia, sino que debe ganarse el derecho al reconocimiento en una exposición de razones que se articula en densos marcos sociales y culturales. La originalidad debe apelar a un sustrato común y el reconocimiento sólo puede darse en la medida en que exista un acuerdo sobre determinados valores, esto es, compartiendo un horizonte de significado que designe como valiosas ciertas aspiraciones. Téngase en cuenta que tratar de modo igual, con la misma consideración y respeto, a todos los miembros 
de una comunidad política, es un principio asentado en las sociedades democráticas liberales, pero su aplicación no implica satisfacer cualquier demanda, sino descubrir conjunta y recíprocamente el bien que justifica su demanda de reconocimiento (cf. Taylor 1991, pp. 51-52).

\section{EXAMINANDO LA ÉTICA DE CHARLES TAYLOR}

Este recorrido por la filosofía práctica de Taylor muestra el interés por conciliar los aspectos deontológicos, que emergen de las éticas de la justicia, con un enfoque sobre la racionalidad del agente humano que, sin renunciar a la perspectiva teleológica, sitúa en el centro de la reflexión ética su aspiración a la «vida buena». En la medida en que esta filosofía efectúa una indagación sobre los propósitos o fines del agente humano, con el objetivo de vincularla a las exigencias que emergen de la justicia y que estas exigencias se plasmen en derechos, su enfoque puede incluirse dentro de las éticas teleológicas o perfeccionistas, y se enmarca en un proceso de reconstrucción de la moral pública que relaciona ética y política.

En esta revisión de la obra de Taylor se ha destacado su interés por ciertos rasgos fundamentales de la identidad humana: la orientación al bien, la libertad situada, la autenticidad, la definición en el diálogo y la lucha por el reconocimiento. Sin lugar a dudas, estas características no son las únicas a las que deba prestar atención una filosofía moral y política, ni constituyen un listado exclusivo y cerrado de capacidades humanas fundamentales, pero no debieran ser dejadas de lado si se pretende construir una ética y una política en relación que, sin renunciar a la autonomía como principio rector de la vida individual y comunitaria, dote a éstas de contenido moral sustantivo y permita el desarrollo de formas de vida florecientes.

Combinando el análisis fenomenológico y hermenéutico, el trabajo de Taylor se detiene en un conjunto de rasgos de la identidad humana que no pueden desestimarse cuando se trata de investigar lo que consideramos apropiado para los seres humanos. Se trata de una filosofía moral que explora las posibilidades de transición entre el vivir natural o biológico y el vivir bien de la condición ética de los humanos. Estas cualidades intermediarias entre el vivir y la vida buena son las que se definen como el «inevitable marco de referencia» en el que se desarrolla la acción del agente humano, y son las que se han intentado dilucidar y sistematizar en el presente trabajo.

Este tipo de teorías son pertinentes porque centran la cuestión explicitando sus supuestos sobre la concepción de la persona y las metas hacia las que debe orientarse la acción moral y política, de manera que el debate conduce a reflexionar sobre la naturaleza de la persona y sus relaciones, así como también sobre los requisitos que debe cumplir la búsqueda de finalidad en la existencia 
humana, sin perder de vista las consecuencias institucionales de estos planteamientos. Probablemente, la cuestión del tipo de organización institucional emergente en el espacio público sea el aspecto menos definido de esta propuesta. Taylor ofrece interesantes apuntes sobre antropología filosófica, pero pueden plantearse objeciones cuando se plantean las repercusiones políticas de su puesta en práctica. A pesar de ello, la deliberación sobre la justificación antropológica que perfilará lo que se considera el bien de la persona y de la comunidad, se convierte en el foco principal de discusión sobre la dirección que la vida ética, en su doble dimensión privada y pública, debe asumir y promocionar.

En este sentido, uno de los propósitos principales de Taylor es dilucidar el concepto de «libertad», clave de bóveda de la teoría ética y política. Su análisis de este concepto le lleva a proponer una noción de «libertad situada» en la que se apela a los contextos de significación generados en comunidad. El problema reside en que estos contextos de significación son complejos, multifacéticos y plurales, lo cual implica que la apelación a la contextualización de la libertad siempre resultará conflictiva e insuficientemente definitoria (cf. Thiebaut 1998, p. 51).

La investigación crítica, no neutral sino evaluativa, de Taylor, en la que se seleccionan algunos elementos de la vida humana, señalándolos más fundamentales que otros, pretende servir de guía para enmarcar la libertad. Pero, de nuevo, la dificultad consiste en que el primero de estos rasgos es la relación que se establece entre el ser humano y el bien, siendo ésta una relación compleja debido a la propia constitución conflictiva de los bienes, a su permanente coexistencia rival y a la ausencia de criterios claros que permitan la jerarquización de los mismos. La vida moral del agente humano se caracteriza por su aspiración a ciertos bienes que lo constituyen a la vez que le sirven de motivación; pero el concepto de «bien constitutivo» que opera a modo de «fuente moral» refiere tanto a la motivación que da la fuerza para obrar, según la conminación del bien al que se atribuye un rango superior, como a la pasividad respecto a aquello que el sujeto valora en más alto grado. El fruto de esta situación es una identidad moral atravesada por la polaridad entre pasividad receptiva y poder movilizador que define la naturaleza de la libertad. Este contraste indica la peculiar situación en la que se encuentra el sujeto moral respecto a su libertad. De ahí la llamada a la «autenticidad» para que el sujeto confiera sentido a esa libertad, orientándose a su modo particular hacia el bien, examinando el relato de su vida y efectuando una exploración vinculada en la que averigüe su yo más íntimo, sus verdaderos deseos en conexión con la naturaleza que lo contiene.

Esta apelación a la naturaleza tiene una doble dimensión, interior y exterior, cuyos ámbitos son mutuamente dependientes. La naturaleza interior remite a la capacidad reflexiva del agente permitiéndole discriminar entre bienes, pero el desarrollo de la reflexividad humana se genera en conexión con la naturaleza 
exterior a través del diálogo con los otros. De manera que la aceptación de los procesos de conformación intersubjetiva de la subjetividad moral nos insta a comprometernos con bienes que sean reconocibles por los otros. Dicho reconocimiento podrá tener lugar cuando los bienes superiores a los que aspiramos se descubran sobre un horizonte de sentido que los salve de la insignificancia. Sin embargo, en este mapa de la vida moral del agente humano cobra especial relevancia la heterogeneidad de esos bienes de rango superior, su existencia diversa y conflictiva, que somete a controversia la idea misma de evaluación de los «bienes superiores» o «hiperbienes». La jerarquización y la elección de un bien por encima de otros reclaman una justificación, y, sobre esta cuestión, aunque puede considerarse que la filosofía de Taylor apunta una serie de indicaciones derivadas de los rasgos humanos que subraya, quedan por definir con precisión los criterios o principios que utiliza la razón práctica para delimitar el contenido de los «hiperbienes». Porque el concepto de «valoración fuerte» que debe servir para detectar los bienes hacia los que orientar nuestras vidas no aporta suficientes elementos de juicio. Taylor pretende responder a esta cuestión en diversos momentos explicando el modo en que opera la razón práctica (cf. Taylor 1985b, pp. 91-115 y pp. 134-151, Taylor 1995, pp. 34-60). En diferentes escritos suyos describe un razonamiento por transiciones de carácter práctico que culmina en el principio hermenéutico de la «mejor interpretación posible» (the best account). Esta argumentación por transiciones acude a la práctica misma para comprobar la validez de una teoría, para descubrir su potencia explicativa, su capacidad para articular y comprender mejor la actividad propia de los agentes. Se trata de una razón que operando por transiciones concluirá la superioridad de una argumentación sobre otra, a través de una comparación que incluirá interpretaciones razonadas. Según este principio de la «mejor interpretación posible», no se tratará de establecer que un planteamiento sea absolutamente correcto, sino de decidir que un planteamiento es superior a otro porque constituye una «ganancia epistémica» (Taylor 1989, p. 72).

Se observa que, en cualquier caso, el razonamiento moral sobre los bienes obliga al sujeto a establecer un lenguaje comparativo lo suficientemente expresivo de sus motivaciones últimas. Pero en un contexto plural en el que coexiste una diversidad heterogénea de bienes y de fundamentaciones últimas, esta descripción del funcionamiento de la razón práctica no es concluyente para justificar la predilección por un bien en lugar de otro. Y si acudimos a la «comunidad» asumiendo que provee al sujeto de los lenguajes de significación que éste utilizará para identificar y discriminar los bienes, entonces deberemos rechazar una definición esencialista o inmutable de esa «comunidad» erigida en comunidad de interpretación; porque, como indica el profesor Lisón, las comunidades «inventan y reinventan las condiciones emocionales y cognitivas desde las que es posible la justificación crítica de los valores, reconocidos histó- 
ricamente como válidos» (Lisón 2008, pp. 131-132). Por consiguiente, fijándonos en la importancia que Taylor concede en sus textos a la «comunidad» como fuente de valor, y obviando el carácter polisémico de tal concepto, no se presta la adecuada atención al hecho de que en las sociedades democráticas actuales las personas se mueven en una multiplicidad de comunidades que influyen y conforman su identidad, resultando que el papel que desempeña la «comunidad» no es definitorio ni aclaratorio para el bien: cualquiera que sea esa «comunidad», incluirá una pluralidad de formas posibles de entender la articulación significativa entre bienes. En este sentido, acierta Carlos Thiebaut cuando afirma que la primacía del ámbito cultural representado por la «comunidad» se vuelve vacía por tautológica, o «inútil cuando pensamos que ese ámbito ya no es, ni puede ser, homogéneo» (Thiebaut 1998, p. 64).

En resumen, vemos que la conflictividad y rivalidad entre los diversos bienes de rango superior que reclaman la adhesión del sujeto parece formar parte ineludible del fondo ético originario de la relación entre el sujeto y el bien. Esta conflictividad inherente a la reflexión sobre el bien es lo que, probablemente, conduce a algunas éticas contemporáneas a proponer una regla procedimental y adoptar una visión restringida del bien en la fundamentación de sus principios de justicia. Dado que algunos consideran que introducir este tipo de consideraciones sobre el bien resta «estabilidad» a las teorías de la justicia e impide el consenso, se opta por abstraer las concepciones sobre el bien o por utilizar un número de supuestos mínimos o una versión «débil» del bien. ${ }^{5}$

Sin embargo, el trabajo de Taylor se erige a contracorriente insistiendo en explorar la función que ejerce la definición de la «vida buena» para la confección de las normas que regulan la convivencia. Otro problema es que en su obra sólo aparezcan alusiones a su contenido y nunca una definición global y completa de la misma que describa sus repercusiones prácticas. Aquí se han destacado algunos rasgos de esta concepción del agente humano que orientaría el contenido de la «vida buena»; pero la elaboración por parte de Taylor de un discurso ambiguo, aunque sugerente, provoca que las concreciones se tornen imprecisas y que aparezcan importantes interrogantes: ¿En qué consiste atender la llamada de la naturaleza en nosotros para descubrir el bien? ¿Cuáles son las resonancias de la naturaleza en nuestro interior? ¿Cómo deben organizarse las instituciones básicas de la democracia en torno a los rasgos que comprende la vida humana? ¿Cuáles son las virtudes cívicas que debe promocionar la comunidad política? ¿En qué sentido son diferentes estas virtudes a las que defiende, por ejemplo, el liberalismo igualitarista? Aunque Taylor of rece algunas pistas sobre el tipo de bienes que pueden ser reconocidos políticamente y constituir

5 Una propuesta de este tipo es lo que persigue el «consenso por superposición» de Rawls (1993, pp. 133-172). 
metas de la acción común, ¿a quién corresponde, en el marco de una sociedad democrática, decidir los bienes que puedan ser objeto de un reconocimiento basado en la diferencia?

A pesar de sus llamamientos a la participación y a la implicación políticas, es difícil que su propuesta sirva, en el plano práctico, para modificar las retóricas políticas de los juegos de poder y su resolución final mediante el procedimiento democrático; o para sustituir, en el plano teórico, el orden y la claridad que aportan las éticas procedimentales. Sin embargo, su propuesta continúa siendo interesante al introducir en el debate ético y político algunas tesis que deben ser consideradas: especialmente, la apelación al bien como un elemento de la vida ética que no puede ser expulsado del discurso de fundamentación teórica, la necesidad de que el sujeto alcance autoclaridad a la hora de evaluar interpretaciones en conflicto y, de modo general, su pretensión de ofrecer una definición de los rasgos del vivir humano que conduzca a una descripción orientadora de la vida buena. Cuando Taylor explora las capacidades fundamentales del agente humano aparecen sus más influyentes reflexiones, sobre todo al analizar las cuestiones relativas a lo que significa la libertad del agente y el sentido de su acción, y también al observar las repercusiones que una visión soslayada de estos aspectos ejerce sobre la ética y la política contemporáneas.

\section{REFERENCIAS BIBLIOGRÁFICAS}

ABBEY, R. (ed.) 2004: Charles Taylor. Cambridge: Cambridge University Press.

ARANGUREN, J. L. L. 1994: Ética, en Obras Completas, II. Madrid: Trotta, pp. 159-502.

ARISTÓTELES, 1989: Política. Madrid: Centro de Estudios Constitucionales.

CONILL, J. 2006: Ética hermenéutica. Crítica desde la facticidad. Madrid: Tecnos.

FLANAGAN, O. 1996: «Identity and Reflection», en Self Expressions. Mind, Morals and the Meaning of Life. Nueva York: Oxford University Press, pp. 142-170

KERR, F. 2004: «The Self and the Good. Taylor's Moral Ontology», en R. Abbey (ed.), Charles Taylor. Cambridge: Cambridge University Press, pp. 84-104.

LAITINEN, A. 2008: Strong Evaluation without Moral Sources. On Charles Taylor's Philosophical Anthropology and Ethics. Berlín: Walter de Gruyter.

LISÓN, J. F. 2008: «Comunitarismo y desarrollo moral: incidencia de los valores comunitarios en el desarrollo moral», en A. Domingo y J. F. Lisón (eds.), Ética, ciudadanía y desarrollo. València: Universitat de València, pp. 127-150.

RAWLS, J. 1993: Political Liberalism. Nueva York: Columbia University Press.

RICOEUR, P. 2008: «Lo fundamental y lo histórico. Notas a Sources of the Self de Charles Taylor», en Lo justo 2. Barcelona: Trotta, pp. 155-170.

SMITH, N. H. 2002: «The Self and the Good», en Charles Taylor. Meaning, Morals and Modernity. Cambridge: Polity Press, 2002, pp. 87-119 
TAYLOR, Ch. 1985a: Human Agency and Language. Philosophical Papers I. Cambridge: Cambridge University Press.

- 1985b: Philosophy and the Human Sciences. Philosophical Papers II. Cambridge: Cambridge University Press.

— 1989: Sources of the Self. The Making of the Modern Identity. Cambridge: Harvard University Press.

- 1991: The Ethics of Authenticity. Cambridge: Harvard University Press.

— 1994: «The Politics of Recognition», en Amy Gutmann (ed.), Multiculturalism. Examining the Politics of Recognition. Princeton: Princeton University Press.

— 1995: Philosophical Arguments. Cambridge: Harvard University Press.

— 1997: La liberté des modernes. París: Presses Universitaires de France.

_ 2004: Modern Social Imaginaries. Durham y Londres: Duke University Press.

— 2007: A Secular Age. Cambridge: The Belknap Press of Harvard University Press.

THIEBAUT, C. 1998: Vindicación del ciudadano. Barcelona: Paidós, 1998.

WEINSTOCK, D. M. 1994: «The Political Theory of Strong Evaluation», en J. Tully (ed.), Philosophy in an Age of Pluralism. The Philosophy of Charles Taylor on Question. Cambridge: Cambridge University Press, pp. 171-193.

RUBÉN BENEDICTO RODRÍGUEZ es Profesor del Departamento de Filosofía de la Universidad de Zaragoza.

Publicaciones recientes:

Educación cívica: democracia y cuestiones de género, Barcelona: Icaria, 2010.

Charles Taylor: Identidad, comunidad y libertad, Valencia: Universitat de València, 2005.

Línea de investigación:

Su labor investigadora de ha centrado en cuestiones educativas y filosóficas relacionadas con la filosofía moral y política, la bioética y la estética.

Dirección electrónica: rubero@unizar.es 